\title{
Falar de Joaquim é falar de Dalton!
}

\author{
Lia Mara de Souza da Silva ${ }^{1}$
}

- Enviado em 28/05/2016

- Aprovado em 18/06/2016

\section{RESUMO}

$\mathrm{O}$ artigo aborda a trajetória da revista Joaquim que nasceu para quebrar com uma hegemonia dominante que se impunha à literatura paranaense há mais de meio século, a do Paranismo, que através de uma elite local criou e apadrinhou o campo das artes paranaenses. Assim sendo, para que se possa entender as mudanças sofridas no campo das correntes literárias curitibanas, e o impacto causado por Joaquim na sociedade paranaense dos anos 1930/50, faremos uma retrospectiva histórica do ambiente cultural a fim de podermos contextualizar o nascimento da revista e em que modo ela pode, em um determinado momento reunir jovens literários dispostos a romper com a dominação do então representativo Movimento Paranista, abrindo espaço para uma outra forma de expressão literária, a dos modernistas.

Palavras-chave: Paranismo, Dalton Trevisan, Revista Joaquim, Modernismo, Literatura Paranaense.

\section{INTRODUÇÃO}

Falar de Joaquim é falar de Dalton Trevisan, seu fundador e principal expoente, figura mística e portadora de um perfil único. Escritor polêmico, contestado por muitos e ao mesmo tempo admirado por outros tantos. Dalton através de Joaquim reuniu artistas literários e poetas, "os jovens de Joaquim" como eram denominados, tinham como foco de provocação a publicação de artigos contra os paranistas, sendo os principais alvos na área artística o poeta Emiliano Perneta (18661921) e o pintor Alfredo Andersen (1860-1935).

No final da década de 1940 e início 1950 todo o país se encontrava em fase de reorganização, pois passava por um período de pós-guerra e pós Estado-Novo, encarando processos crescentes de urbanização, industrialização e remodelação dos meios de comunicação que alargaram consideravelmente a circulação de informações. O surto industrial dos anos de guerra, a imigração e consequentemente a urbanização por que passávamos nos revestiam com atributos de

\footnotetext{
${ }^{1}$ Graduada em Serviço Social. E-mail: pcrcheguemara@ hotmail.com
} 
um novo Brasil. São Paulo, com sua acentuada industrialização, já podia ser comparada aos grandes centros europeus.

Esse processo de organização crescente da urbanização e industrialização aumentou consideravelmente as discussões nacionalistas. A inovação dos meios de comunicação divulgava as informações e novidades para além do eixo Rio/São Paulo. Nessa época, Curitiba já dispunha, desde o início do século XX, de certa inovação tecnológica junto a sua principal atividade econômica - o cultivo da erva-mate. Esta industrialização desenvolvida durante o ciclo ervateiro servirá como impulso à urbanização em uma cidade que na virada do século XX já apresentava um significativo crescimento populacional. A cidade já era considerada um centro político, econômico, militar, cultural e estudantil, desde à criação da primeira universidade do Brasil em 1912 (VANALI, 2013).

Todo este contexto histórico desencadeia mudanças sócio culturais. Assim sendo, encontramos no campo das artes o Simbolismo, corrente estética literária que surgiu na França no final do século XIX, em oposição ao Naturalismo e ao Realismo. Tinha como característica desmistificar totalmente a poesia do tom divino, trazendo uma poesia irreverente e ansiosa de liberação. Reagia contra tudo que representava o materialismo e racionalismo e pregava o subjetivismo, o misticismo e a sugestão sensorial. Procuravam utilizar de uma linguagem que pudesse sugerir a realidade em vez de retratá-la de maneira óbvia, utilizando de símbolos, imagens, recursos sonoros e cromáticos (FABRINO, 2014). Para Fabrino (2014, p.241): “as palavras não eram o suficiente, elas deviam evocar, não descrever, sugerir e não definir, o que resultou no símbolo: uma representação com tentativa de simbolizar por meio de metáforas”.

Na década de 1930 a literatura local era caracterizada pelo Movimento Simbolista, tendo como representante maior o escritor Emiliano Perneta considerado o "Príncipe dos Poetas Paranaenses". Bega (2013) realizou um levantamento dos demais representantes da geração simbolista, chegando aos seguintes autores: Rocha Pombo, Domingos do Nascimento, Leôncio Correia, Nestor de Castro, Nestor Vitor, Dario Vellozo, Júlio Perneta, João Itiberê da Cunha, Ricardo de Lemos, Silveira Netto, Santa Ritta, Romário Martins, Euclides Bandeira, José Gelbecke, Aristides França e Adolfo Werneck, citando ainda os neo-simbolistas Andrade Muricy e Tasso da Silveira.

Já o Parnasianismo é um movimento literário que surgiu na França no século XIX em oposição ao Romantismo, muito valorizado pelas camadas cultas da sociedade até os primeiros anos do século XX. O termo parnasianismo teve origem na mitologia grega que havia dado esse nome a uma montanha consagrada a Apolo e às musas de Monte Parnaso. Sua característica é a 
sacralidade da forma e respeito às regras de versificação, preciosismo rítmico, rimas raras e preferência por estruturas fixas. Ao contrário do Simbolismo não emprega a linguagem figurada, valoriza o exotismo dando preferência a atos históricos, objetos e paisagens. Percebe-se uma descrição visual forte da poesia, sendo a sonoridade das palavras e dos versos sua preocupação central. (FABRINO, 2014).

\section{Segundo o Professor Doutor Ivan Justen Santana ${ }^{2}$ :}

São raríssimos os poetas classificados como parnasianos haja vista a dominância do Simbolismo aqui, desde a eclosão do movimento (com a formação do grupo de "O Cenáculo", revista publicada em 1895), até os falecimentos dos autores principais (Emiliano Perneta, em 1921; Dario Vellozo, em 1937; e Silveira Neto, em 1942). O único poeta de projeção, que era paranaense, e que costuma ser incluído entre os parnasianos brasileiros, é Emílio de Meneses. Outros poetas paranaenses que podem ser associados ao Parnasianismo são os pouquíssimos conhecidos Leôncio Correia (Paranaguá, 1865 - Rio de Janeiro 1950) e Euclides Bandeira (Curitiba, 1876 - 1947) autores cuja poesia permite associação ao movimento poético do Parnasianismo. Outro que também pode ser lembrado, a propósito, é Reinaldino Scharffenberg de Quadros (São José dos Pinhais, 1878 — Rio de Janeiro, 1929).

O Modernismo, por sua vez, surge na Europa e se espalha pelos Estados Unidos nos primeiros anos do século $\mathrm{XX}$, sendo um amplo movimento cultural que repercutiu sobre a cena artística e literária brasileira na primeira metade do século XX. A tendência dos escritores desta época era evitar tipos formais e tradicionais em busca de novos formatos literários do período que antecedeu a Primeira Guerra Mundial, a partir da assimilação de tendências culturais e artísticas lançadas pelas vanguardas europeias, como o Cubismo e o Futurismo, novas formas de linguagem trazidas pelos movimentos europeus e assimilados pelo contexto artístico brasileiro. (FABRINO, 2014). Neste contexto histórico os anticlericais ${ }^{3}$ já se encontravam bastante desgastados ao chegar dos anos 40. A religião havia sido institucionalizada com a subida ao poder de Getúlio Vargas, que implementou o ensino religioso católico nas escolas públicas, e o livre pensar crítico dos anticlericais já não era mais bem-visto em uma ditadura.

\footnotetext{
${ }^{2}$ Professor Doutor do Centro Universitário UNINTER e pesquisador da literatura paranaense em entrevista cedida à autora em 23/05/2015.
}

\footnotetext{
${ }^{3}$ Anticlericais assumem grande influência no campo das ideias, sobre tudo após sua associação ao Simbolismo, que irá delinear-se em 1894-1898 com a orientação literária dos principais poetas simbolistas, sem ataques diretos à doutrina católica, mas na divulgação do ensino laico, do livre arbítrio, liberdade de expressão, defesa da população indígena e formação do homem brasileiro. Seus principais expoentes serão Rocha Pombo, Dario Vellozo, Julio Perneta, Silveira Netto e Emiliano Perneta (BEGA 2013).
} 
Emiliano Perneta, acompanhado dos escritores Leôncio Correia, Emilio de Menezes, Sebastião Paraná, Venceslau de Queiroz, Rodrigo Otávio, Leopoldo de Freitas, Dias da Rocha Filho, Horácio de Carvalho, Julio Prestes, Gonzaga Duque, Lima Campos, Nestor Victor, entre outro, além de introduzir entre os paranaenses a obra de Charles Bauldelaire, também foi o nome central do Simbolismo paranaense na virada do século XIX para o XX e uma das figuras de maior proeminência que dominavam as letras e referências culturais paranaenses na época da criação de Joaquim. É, portanto essa a geração a ser batida pelos moços de Joaquim, os quais desenvolveram importante referência cultural no já Estado do Paraná e que viria a resultar no Paranismo, criado em meio àquele caldeirão sóciopolítico-econômico-cultural que se deu após a emancipação da província, tudo em pouco mais de meio século, período que também viveu a abolição da escravatura e a proclamação da República (MELLO, 2008).

Com a chegada ao poder de Getúlio Vargas, em 1930, o Movimento Paranista teve que conter suas intenções propagandísticas, pois a ditadura que se seguiria priorizava a prospecção e manutenção dos símbolos nacionais e nacionalistas aos regionais. Mas o Paranismo não seria desmantelado, sobreviveria como ideia e principalmente como arte pictórica. $\mathrm{Na}$ literatura, no entanto, ficava mais restrito aos discursos de apologia do que a obras ficcionais. Faltava-lhe maior produção. Os intelectuais que produziam, viviam o dilema de o fazerem para um público bastante restrito, principalmente porque ficavam circunscritos aos leitores locais.

No Paraná, a discussão em termos de cultura moderna e tradicional é colocada pelo menos desde fins dos anos quarenta. A integração com os problemas sociais contemporâneos e os debates sobre a função da arte e da literatura se tornam uma constante luta acirrada, e Dalton Trevisan, Erasmo Pilotto e Antonio Walger serão os divisores de águas na cultura local.

\section{DALTON TREVISAN}

Não vou responder às perguntas simplesmente porque não posso, é verdade; sou arredio, ai de mim! Incuravelmente tímido (um pouco menos com as loiras oxigenadas!)." Já se escreveu e se comprovou que os demais vampiros não podem encarar, sem pânico, um crucifixo. Ou réstias de alho, água corrente cristalina... Dalton não pode ver um jornalista. Vendo, foge, literalmente foge apavorado. Suas raras fotos surgidas na imprensa foram feitas às escondidas. ${ }^{4}$

\footnotetext{
${ }^{4}$ Disponível em http://www.releituras.com/. Projeto Releituras Arnaldo Nogueira Jr. Acessado em 20/04/2016.
} 
Dalton Jérson Trevisan, contista considerado uma das maiores expressões na literatura brasileira nasceu em 14 de junho de 1925 em Curitiba. Enigmático estudante de Direito, costumava lançar seus contos em modestos folhetos, arriscando a publicação praticamente caseira dos livros Sonata ao Luar (1945) e Sete Anos de Pastor (1946), obras mais tarde renegadas por ele. Declara não possuir um exemplar sequer dos livros e "felizmente já esqueci aquela barbaridade" (ANDRIOLI, 2013 p.23).

Entre 1946 e 1948, editou a revista Joaquim, "uma homenagem a todos os Joaquins do Brasil", periódico composto de poucos números (total de vinte e um) reunindo intelectuais de peso, críticos, poetas e renomados escritores. A década de 1950 foi para ele marcada pela dificuldade de colocar seus livros no círculo comercial, o que faz com que o mesmo distribuísse exemplares pelo correio a amigos e conhecidos de forma artesanal (ANDRIOLI, 2013).

Dalton Trevisan foi sempre contrário as fotografias e jamais dava entrevistas. Um exemplo desse comportamento ocorreu em 1959 quando lançou o livro Novelas Nada Exemplares o qual reunia uma produção de duas décadas, e recebeu o Prêmio Jabuti da Câmara Brasileira do Livro conquistando o grande público, mas a fim de manter sua imagem enigmática, não foi buscar o prêmio, enviando um representante (ANDRIOLI, 2013).

Escreveu, entre outros, Cemitério de elefantes e Morte na praça, ambos os contos de 1964 onde retrata o universo da Curitiba provinciana, Guerra conjugal (1975), um de seus livros que foi transformado em filme. Suas obras foram traduzidas para diversos idiomas: espanhol, inglês, alemão, italiano, polonês e sueco. Dedicando-se exclusivamente ao conto, acaba tornando-se o maior mestre brasileiro no gênero, e só teve um romance publicado: "A Polaquinha" (1985). Em 1996 recebe o prêmio Ministério da Cultura e Literatura pelo conjunto de suas obras, mas mantém a atmosfera de suspense em torno da sua pessoa, recusando ir receber o prêmio, o que o consagra como um personagem enigmático e acaba recebendo o apelido de "Vampiro de Curitiba", título de um dos seus livros (NUNES FILHO, 2006).

Em 1965 publica o livro que deixa célebre seu personagem mais representativo, $O$ Vampiro de Curitiba (1965), com o personagem "Nelsinho", que encarna a figura do moço modesto e recatado, que transcorre suas jornadas nas ruas curitibanas em busca das fêmeas (de preferência uma polaquinha), e o mesmo só pode viver graças a sua vítima (ANDRIOLI, 2013). 
Para Alberto, 2013, p.1:

\begin{abstract}
Cada conto ou episódio é pungente na ironia, indiscreto nos detalhes psicológicos, perverso na imagística. Nelsinho triunfa como símbolo do desespero universal. No contexto das histórias de Dalton Trevisan, ser mulher no Brasil é morar no inferno. Sedutora ou vítima são os únicos papéis a ela reservados. Se encontra prazer no sexo, ou ela é pecaminosa ou foi pelo homem arrastada a sentí-lo, apesar de si mesma. Os homens brasileiros encarnados em Nelsinho, o "vampiro" curitibano - não são melhores: odeiam e adoram a mulher, assim condenados a perseguí-la sem descanso. É um mundo sórdido, sem solidariedade e sem esperança. A ironia começa com o diminutivo do nome do personagem.
\end{abstract}

Segundo Andrioli (2013), Dalton Trevisan em 1968 conquista o primeiro lugar no I Concurso Nacional de Contos do estado do Paraná. Neste evento ele se esquivava de jornalistas, mas se viu na obrigação de dar duas entrevistas a jornais paranaenses da capital, o que despertou muita curiosidade pelo fato do mesmo se dispor a dar respostas aos jornalistas, os quais com ironia comentam o fato, que vem respondido por Dalton Trevisan da seguinte maneira: "mas encontrar Dalton Trevisan não é tão dificultoso como dizem muitas pessoas e alguns jornais. A resposta é esta: tanto não é difícil alguém me encontrar que eu esbarro comigo mesmo diariamente em todas as esquinas de Curitiba”(ANDRIOLI, 2013, p. 24).

Em 2003, divide com Bernardo Carvalho o maior prêmio literário do país $-1^{\circ}$ Prêmio Portugal Telecom de Literatura Brasileira - com o livro "Pico na Veia". Publica um total de 44 livros, dos quais cinco no exterior, assim como, antologias alemãs, argentinas, americanas, polonesas, sueca, venezuelana, dinamarquesa e portuguesa. Lançou, em 1975, o filme A Guerra Conjugal, com história e diálogos do autor, roteiro e direção de Joaquim Pedro de Andrade 5 .

\title{
2. A REVISTA JOAQUIM.
}

Joaquim é uma revista de ação, divulgação, agitação e tensão cultural que nasceu em Curitiba na década de 40, e durou 21 edições entre abril de 1946 e dezembro de 1948. Teve como principal mentor e agitador o então jovem e iniciante escritor Dalton Trevisan, acompanhado, por

\footnotetext{
${ }^{5}$ Informações obtidas junto à página da Editora Record e artigos publicados pelo jornal "O Estado de São Paulo", de autoria de José Paulo Paes e João Antônio, em 20/07/96. Disponível em: http://www.releituras.com/daltontrevisan_bio.asp. Acessado em 26/05/2016.
} 
um breve período, de Erasmo Pilotto ${ }^{6}$ e de Antônio P. Walger ${ }^{7}$. A publicação foi um marco local e teve boa repercussão fora do Paraná. Localmente, foi representativa e marcou um determinado momento histórico cultural que marcou uma mudança de rumos na produção artística.

Pelo próprio título de Joaquim, um nome escolhido por ser comum, indicava assim a preferência, manifestada em muitos dos temas dos moços da revista (notadamente, Poty e Trevisan $)^{8}$, pela temática social que enfocava o homem, e frequentemente o trabalhador, e seu meio. Nesse sentido, de valorização do comum, é que a revista Joaquim porta em todas as suas edições a frase "em homenagem a todos os Joaquins do Brasil".

Quando Dalton Trevisan teve a ideia da criação de Joaquim, foi Erasmo Pilotto, pertencente a uma geração anterior a dele que acolheu a ideia. Erasmo Pilotto fez parte da direção da revista, participando com textos até seu quarto número. Esses moços, como eram chamados pertenciam a uma nova geração de escritores que, assim como Dalton Trevisan reivindicavam uma arte comprometida com a vida e com o cotidiano das pessoas, proclamando uma nova modernidade, pois segundo eles, os demais fariam parte de um tempo pretérito, sendo que assim como Emiliano Perneta, todos os demais viviam em uma Torre de Marfim, afastados da vida cotidiana que corria nas ruas nas praças, liceus e fábricas. Dalton critica Emiliano Perneta em uma de suas publicações ressaltando a sua hegemonia, e escreve que, aquele que havia sido há algumas décadas aclamado o príncipe dos poetas paranaenses, tinha qualidades literárias questionáveis e o denomina - Emiliano poeta mediocre:

\footnotetext{
${ }^{6}$ Erasmo Pilotto nasceu em Rebouças, no Paraná no dia 21 de outubro de 1910. Faleceu em Curitiba em 1992. Intelectual ligado as questões educacionais no cenário paranaense. Professor, escritor, político e crítico, interveio em diversos campos da cultura: da pedagogia às artes plásticas, da filosofia à literatura. Pilotto se notabilizou pelos estudos e pelas intervenções que realizou sobre o processo de organização da escola pública e, em especial, sobre os processos de formação de professores. http://www.sbhe.org.br/novo/congressos/cbhe4/coordenadas/eixo06/Coordenada\%20por\%20Carlos\%20Eduardo\%20Vi eira/Carlos\%20Eduardo\%20Vieira\%20-\%20Texto.pdf. Acessado em 29/05/2016. Ver também VIEIRA (2006).
}

\footnotetext{
${ }^{7}$ Antônio P. Walger, o mais prático deles, que cuidava da administração e subsistência da revista (OLIVEIRA, 2005). Não foram encontrados mais dados de Antonio Walger.

${ }^{8}$ Colaboradores da Revista Joaquim, Erasmo Pilotto (1910-1992), Wilson Martins (1922), Euro Brandão (1924-1999), Temístocles Linhares (1905-1993), Carlos Drummond de Andrade (1902-1987), José Paulo Paes (1926-1998), Portinari (1903-1962), Di Cavalcanti (1897-1976), Vinícius de Moraes (1913-1980), Otto Maria Carpeaux (19001978), Sérgio Milliet (1898-1966), entre outros (OLIVEIRA, 2005).
} 
Emiliano Perneta foi uma vítima da província, em vida e na morte. Em vida, a província não permitiu que ele fosse o grande poeta que podia ser, e, na morte, o cultua como sendo o poeta que não foi. Há no Paraná, por razões sentimentais, a mística de Emiliano, que não tem raízes na admiração dos moços; eles não a aceitam e repudiam. [...] Emiliano fez poesia, como se fez poesia naquele tempo, afim de ser recitada nas sessões lítero musicais dos colégios em festa no dia da árvore. E, precisamente, sua poesia, borrifada em água de flor, é uma POESIA DE DIA DA ÁRVORE. Versos bonitos, com sonoridade de sílabas de encher bochechas, mas por acaso poesia é mais do que isso? Se é, Emiliano não é poeta. ${ }^{9}$

Como podemos observar, assim como os simbolistas se fizeram modernos valorizando o universal e atemporal, agora os modernistas dos anos 1940/50 voltam-se para o cotidiano e a localidade. A arte reivindicada por Dalton Trevisan, voltada ao local e a cotidianidade era reflexo do que já nacionalmente havia gerado o movimento artístico de 1922 que agitou São Paulo onde se refutou modelos importados a favor de temáticas nacionais.

Tais preocupações refletem-se nas ilustrações que se espalham por Joaquim, seja nas obras de Poty Lazzarotto e Guido Viaro, seja nas obras de jovens artistas como Nilo Previdi, Blasi Júnior, Gianfranco Bonfanti ou mesmo nas de artistas consagrados como Di Cavalcanti e Cândido Portinari.

Para demonstrar que existia essa preocupação em retratar a localidade, podemos prender como exemplo dois artigos de Dalton Trevisan os quais trazem a descrição clara de uma "provincilização" da qual Dalton Trevisan era acusado. O primeiro intitulado "Canto de Sereia", publicado em Joaquim n 3 de julho/1946, e o segundo intitulado "Notícia de jornal", publicado em Joaquim n 2 de Junho/1946, ambos com texto de Dalton Trevisan e gravura de Poty Lazarotto

O primeiro conto, "Canto da Sereia", é a história de um jovem chamado Serafim, arrimo de família que trabalha para ajudar sua mãe a sustentar seus irmãos mais novos. Dalton Trevisan o descreve como um jovem triste, pobre e com escassez de beleza. Veste-se de terno para trabalhar, mas suas roupas não condizem com a imagem que tenta passar, pois são muito surradas. Vive num mundo de sonhos, onde toda a noite quando espera o bonde sonha pegar um trem viver belas aventuras com lindas mulheres, sem preocupações, ir para cidades grandes, mas era temente a Deus. Enfim ao chegar o bonde, em meio as pessoas cansadas se coloca em pé e o sonho volta a invadi-lo, e houve a voz de uma bela sereia que o chama para a vida. Assim termina o conto, que demonstra a vida normal de um rapaz da província curitibana naqueles anos em que Curitiba ansiava de novidades, e sonhava a modernidade.

\footnotetext{
${ }^{9}$ TREVISAN, Dalton. Emiliano, poeta medíocre. IN: Joaquim - revista mensal de arte. Curitiba, junho de 1946. N. $^{\circ} 2$, p.16.
} 

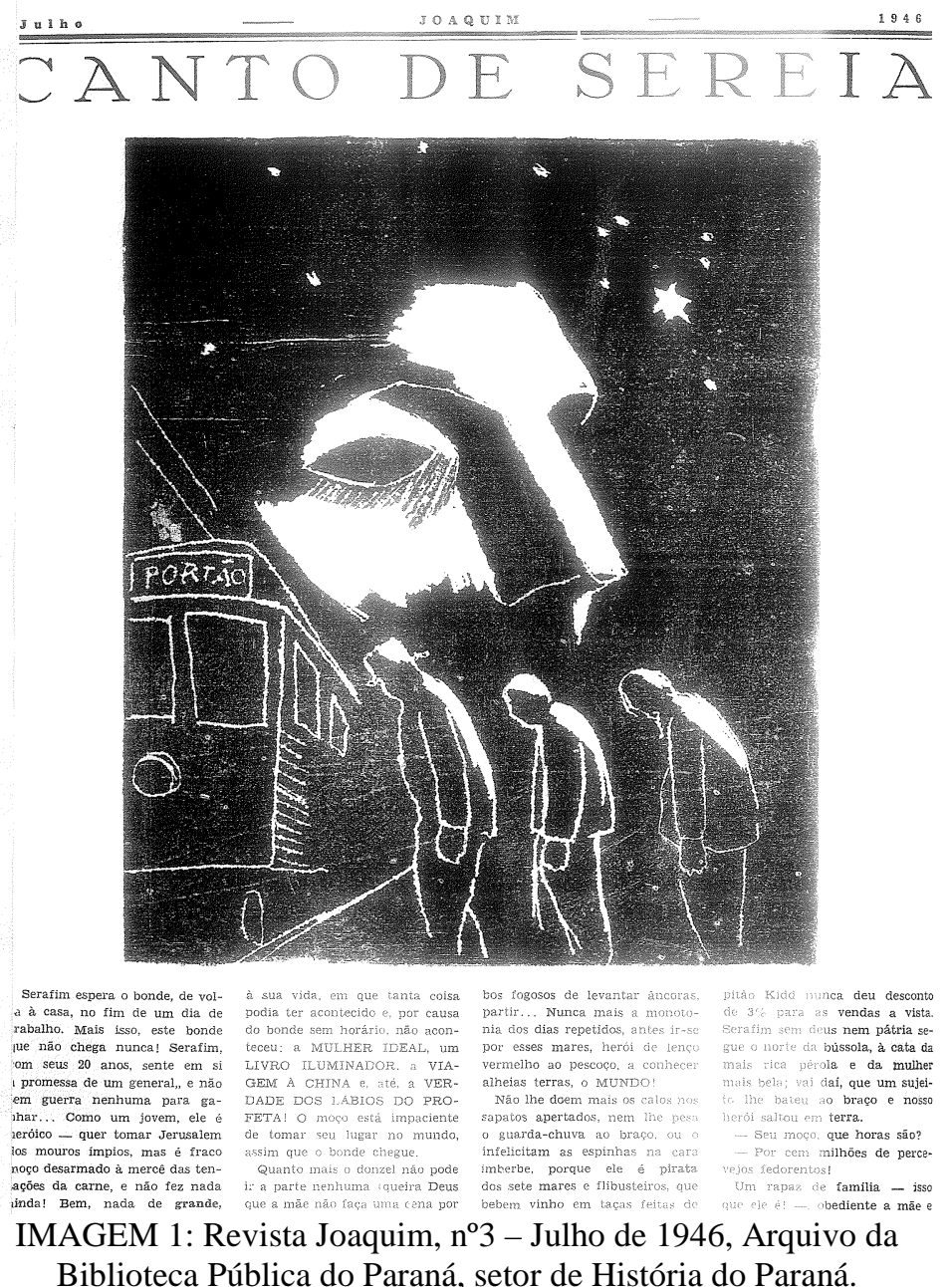

No segundo conto, "Notícia de Jornal", Dalton Trevisan descreve a história de um homem simples, chamado Raimundo, caixeiro viajante apaixonado por Maria da Luz. Raimundo era homem religioso, mas somente pelo fato de que, pela sua obsessão por Maria, rezava toda a noite Uma Ave-Maria para que não fosse deixado por sua amada. Infelizmente não obtém sucesso, ela visa algo mais. Ela o deixa por outro, e um dia destruído pelo ciúme e mergulhado no mundo do álcool, encontra Maria a passear com sua amiga na Praça do Patriarca, toda sorridente a olha e a cumprimenta com a cara de um mendigo, um pedinte na porta de um palácio (ela). Mas Maria o olha com um olhar como se o apunhalasse como quem fecha mais uma porta. Raimundo não suporta tanto desprezo, mas assim mesmo ele pergunta se ela quer volta, e ela debochadamente diz que não. Sua resposta não teria sido tão dolorosa se não houvesse sorrisinhos de sua amiga. Raimundo perde a razão e dispara tiros ao acaso, tendo um deles acertado sua amiga no braço e 
outro a cabeça de Maria, sendo fatal. Assim o encontra a polícia, de joelhos, paralisado, perdido. Assim se lerá no jornal a descrição da cena: “Ontem, às 4 horas da tarde, na Praça do Patriarca, desenrolou-se rápida cena de sangue, em que um caixeiro, fazendo uso de seu revolver, assassinou a antiga amásia" 10 .

Como se podemos perceber mesmo neste texto fica clara a "provincialização" de Dalton Trevisan e de Poty, com personagens pertencentes a cotidiano da nova província. Desta vez observamos declaradamente que Poty também retrata Curitiba, pois como podemos ler no "ônibus" com a escrita "Portão".
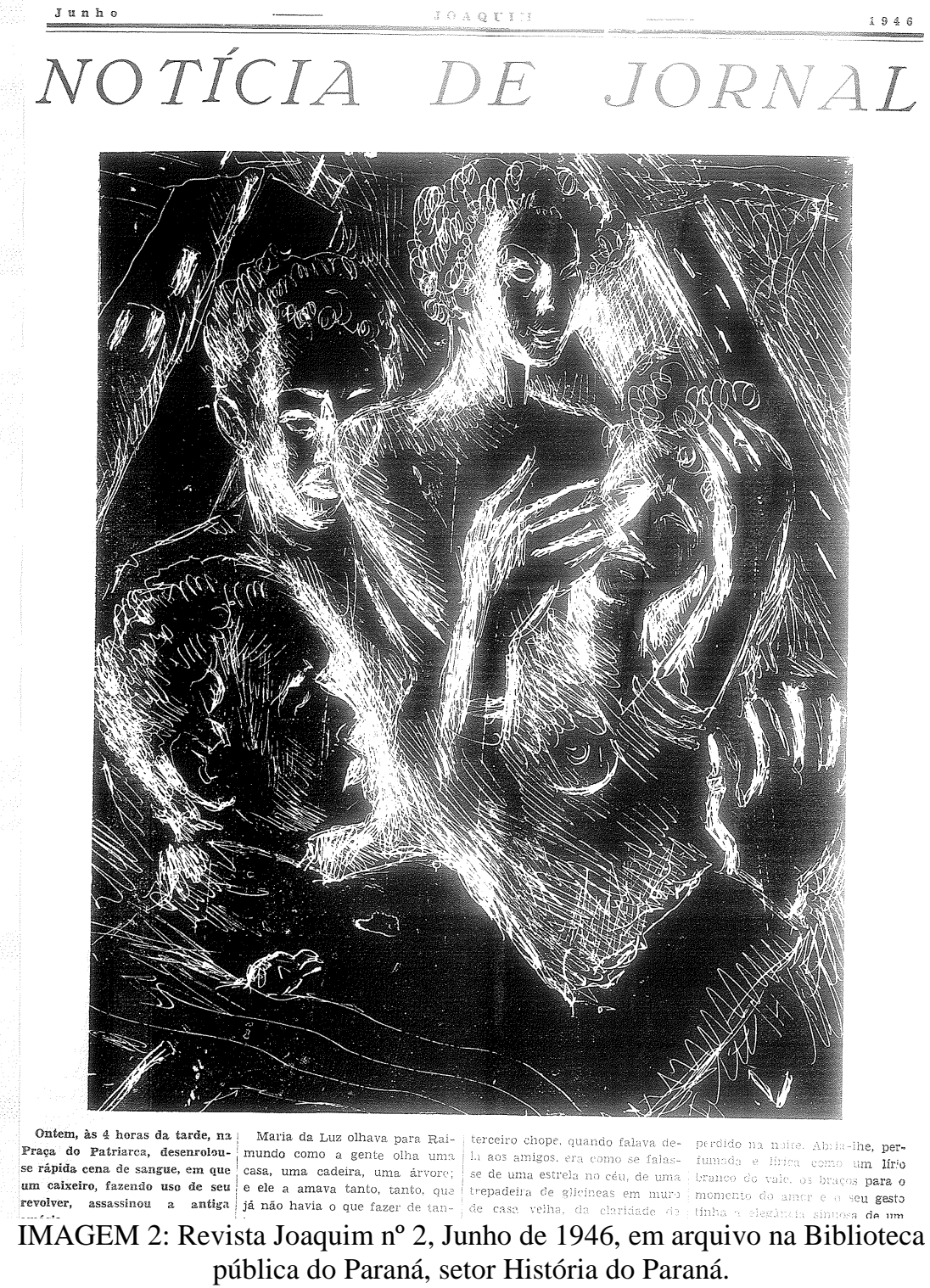

${ }^{10}$ TREVISAN, Dalton. Notícia de jornal. Joaquim. Curitiba, no 2: junho de 1946, p.10. 
Embora a revista tenha em seu quadro de escritores, sobretudo homens das letras como Temístocles Linhares, Wilson Martins e o próprio Dalton Trevisan, e apesar da maximização dessa frente se ter robustecido graças à publicação de textos de Antônio Cândido, Sérgio Milliet, a figura do inimigo encarnava-se na poesia de Emiliano Perneta e na pintura dos discípulos de Alfredo Andersen, o "pai da pintura paranaense". Andersen foi um competente artista norueguês que por aqui chegou em 1893 (permanecendo até sua morte, em 1935) e fez escola ${ }^{11}$. O ambiente cultural paranaense dispunha de poucas informações sobre arte e ainda predominava a arte tida como academizada, assim denominada pelos "discípulos de Andersen". Havendo esse academicismo ferrenho e inimigo de tudo que representasse inovação trazia como fruto, várias gerações de pintores que se repetiam. Acadêmicos que originários do mestre Alfredo Andersen, por gerações e gerações reproduziram o que o mestre havia ensinado, sem se preocupar com pesquisas ou inovações.

Curitiba na época não possuía quase nenhuma informação sobre arte, a não ser a biblioteca pública, recém-inaugurada onde se encontravam alguns livros. Os jovens que pretendiam fazer arte mais avançadas, novas, ansiavam o acesso a revistas que traziam a influência europeia da arte impressionista, de que muito se falava, mas pouco se sabia. A própria Escola de Belas Artes, única no Estado reproduzia certos métodos didáticos conservadores sem estimular a reflexão cultural da modernidade.

Em pleno desfavor a essa tendência, contrapunha-se a imagem de uma arte universal e moderna, encarnada por sua vez pelo escritor Dalton Trevisan e pelo pintor Guido Viaro ${ }^{12}$. Mas a grande influência na produção literária assim como na produção artística, de uma arte figurativa, não se mostrava como uma ruptura absoluta com os valores tradicionais que ainda informavam o artista do Paraná.

\footnotetext{
11 Alguns discípulos de Alfredo Andersen Estanislau Traple (1893-1958), Frederico Lange de Morretes (1892-1954), Gustavo Kopp (1891-1933), João Ghelfi (1890-1925), Theodoro De Bona (1904-1990), Waldemar Curt Freyesleben. (1899-1970). Disponível em: http://www.maa.pr.gov.br/modules/conteudo/conteudo.php?conteudo=19. Acessado em 26/05/2016.

${ }^{12}$ Guido Pellegrino Viaro (1897-1971). Pintor, gravador, aquarelista. Foi o artista moderno mais importante do Paraná. Embora nascido na Itália, seu trabalho artístico foi praticamente todo desenvolvido no Brasil. Não foi apenas o pintor, foi desenhista, gravurista, escultor e um eterno pesquisador. Destacou-se no campo das artes e introduziu a pintura moderna no Paraná. Conseguiu romper os laços com a pintura acadêmica, apresentando uma nova proposta artística sobre os novos movimentos das artes mundiais.
} 


\section{DALTON NA MIRA DOS CRÍTICOS.}

A imprensa e os críticos literários brasileiros passam a se alimentar da figura enigmática criada por Dalton Trevisan, e os papéis se revertem. O Vampiro de Curitiba, que tanto fez para se esquivar da imprensa, torna-se o principal alvo da mesma, a qual agora Vampiriza o Vampiro.

Gostaríamos de resaltar que dentre todas as argumentações utilizadas a fim de criticar o estilo literário utilizado por Dalton Trevisan, o tema que mais permaneceu presente na avaliação da crítica foi o uso da "repetição" dos temas e personagens nas obras de Dalton Trevisan. Por outro lado, temos uma crítica que defende a ideia contrária, de que não há repetição nos escritos do autor, mas sim reinvenção (MONTEIRO, 2013).

O crítico Otto Maria Carpeaux por algum tempo desempenhou o papel do crítico obcecado, e quando Dalton Trevisan lança "Novelas nada exemplares", o acusa de ser pretensioso, de utilizar da "vida de gentes primitivas" em seus textos, ser trivial, com abordagens absurdas, inadequado na escolha dos personagens e universo retratado, censurando também sua reincidência.

As críticas prosseguem com o tempo, e em 1973 Duílio Gomes faz sua contribuição, após ter resenhado "O Rei da terra", deixa um comentário onde demonstra desconfiança e dúvida sobre sua própria crítica:

$\mathrm{Na}$ verdade, ele não acrescentou nada neste seu ultimo livro de contos [...] Mas, por outro lado, sou obrigado a confessar que, [...] E se um cara possui a força de nos fazer lembrar de outras estórias lidas há seiscentos anos atrás, ele não está tão murcho assim (MONTEIRO, 2013, p.28).

Como podemos observar, ele critica e se retrata, e em outra crítica feita pelo mesmo autor, onde escreve: "É verdade que achei "Desastres de amor" e "A guerra conjugal” puro lixo, mas não se pode condenar um escritor porque ele escreve mais de cem contos onde os personagens são, em todos eles, João e Maria” (MONTEIRO, 2013, p.35).

Se observarmos mais este trecho da mesma crítica que Duílio Gomes publica, onde diz: "[...] Qual anjo torto mandou Trevisan desafinar dessa maneira o contente conto-brasileio? Estamos perplexos. Felizmente. Tem alguém que nos intriga.” Já neste trecho podemos constatar que existe uma aceitação da perplexidade como algo positivo, pelo uso do advérbio "felizmente", e que esta aparente contradição revela um indício daquilo que poderíamos entender como uma crítica ainda em formação ou em construção" (MONTEIRO, 2013 p.138).

Outro crítico, Antônio Dimas, não deixa claro se quis censurar a "repetição", abrindo a possibilidade de estar afirmando que pode ser uma "repetição intencional", como marca de seu 
estilo, sem se importar com as críticas. Em 1978, Wamiltton Cardoso Afonso acusa a "repetição" de modo mais diplomático, comparando-o a Beethoven e Di Cavalcanti, dando a repetição de Dalton um aspecto positivo, como objeto estético. No mesmo ano, Jorge de Souza Araújo nos deixa sua mensagem diferenciada das anteriores com relação à repetição e afirma que a lógica da repetição tem um significado muito claro: nós vivemos dentro de histórias que se repetem”. E acrescenta, "Dalton não se repete por limitação, mas porque o autor entende a vida assim, como uma repetição. A repetição existe, mas é intencional" (MONTEIRO, 2013, p.127). A mesma autora ainda comente que:

\begin{abstract}
Na década de 80 a crítica jornalística continua defendendo a ideia de que a repetição faz parte de um projeto estético e deixa de ser vista como falta de criatividade do autor. Assim sendo passa a ser interpretada como fazendo parte da intencionalidade, da existência de um projeto estético, que passa a ser buscado e interpretado. A leitura se desloca ao âmbito acadêmico, aproximando a crítica de jornal da crítica universitária (MONTEIRO, 2013, p.135).
\end{abstract}

Para Wilson Martins a repetição é uma forma utilizada por Dalton Trevisan para forçar os críticos a se repetirem ou a silenciarem, pois "se Dalton se repete, nada mais resta à crítica do que também se repetir nas suas avaliações" (MONTEIRO, 2013, p. 142).

Nessa breve análise percebemos que as críticas em torno das obras de Dalton Trevisan fizeram com que o autor passasse do anonimato para a fama por seu comportamento de aversão à publicidade. Com sua atitude sinistra de escapar das entrevistas e fotógrafos tornou-se público mais rapidamente do que o esperado. Observamos que a crítica neste caso não conseguiu destruir o autor, nem deixá-lo no anonimato, muito pelo contrário, fez com os próprios jornalistas e críticos literários tivessem que repensar suas críticas, pois as mesmas estavam se tornando repetitivas, e de acusadores poderiam ser acusados.

Mesmo o foco das críticas, as repetições, que no início eram vistas como imaturidade, falha, falta de criatividade, etc passam a serem interpretadas como virtude, estilo, estratégia, projeto e intencionalidade.

\title{
CONSIDERAÇÕES FINAIS
}

Procuramos expor a polêmica gerada em torno da Revista Joaquim, criada por Dalton Trevisan, a qual através de seus colaboradores, dentre os quais, poetas, escritores e artistas 
plásticos, dedicaram seus trabalhos na formação de algo que falasse sobre as convicções da nova geração literária. A "geração de 45" como ficaram conhecidos os "Moços de Joaquim" se debateram contra o Simbolismo, corrente literária que predominava naquele momento no cenário artístico cultural paranaense. Estas disputas se viam claramente entre as páginas da Revista Joaquim, onde podemos encontrar contos, poesias e críticas contra os Simbolistas e defesas ao Modernismo, corrente literária de cunho francês (MELLO, 2008).

Como já pudemos observar "os moços de Joaquim" atacam o Simbolismo e pregam o Modernismo, acusam Romancistas, Parnasianistas e Simbolistas de arcaicos, atrelados às tradições, pois ser moderno era abrir-se para o mundo e deixar de ufanizar seu país ou mesmo seu Estado, como faziam os Paranistas. Estamos de acordo com relação à modernização, mas infelizmente nosso país parece sofrer de uma personalidade titubeante, pois tendemos a pegar de empréstimo, mesmo que tardiamente, pela imitação passiva, do que vem de fora, pois, todas as evoluções de correntes literárias pelas quais passamos, em particular as três ultimas citadas acima, vieram da Europa, chegando aqui com um considerável atraso ${ }^{13}$.

Assim sendo, mesmo os "moços de Joaquim" através da influência europeia combatem o tradicional e o arcaico, e seu maior representante Dalton Trevisan se contradiz, visto que em seus contos vem acusado de provincianismo, por utilizar-se de personagens pertencentes ao cenário curitibano, e suas tramas se desenvolverem em nossas praças e ruas, ele mesmo se diz reflexo das pessoas que circulam nas ruas. Quem criticava o ideal Paranista, agora possui como ideal Curitiba e sua gente como inspiração.

Retomando a aversão de Dalton Trevisan com relação a imprensa, segundo Andrioli (2013, p.111):

\begin{abstract}
"Dalton Trevisan tinha um comportamento obsessivo com relação a reescrita, pois ele tenta aprisionar as palavras ao seu comando, para que sejam lidas de acordo com o seu pensamento atual, assim sendo ao recolher e reescrever cada conto, impede que o texto morra. Para Dalton Trevisan a obra se torna mortal a partir do momento que for publicada. Mas uma palavra grafada em um jornal, por mais perecível que seja, tem vida maior em relação aos contos".
\end{abstract}

Sendo a reescrita um hábito permanente no autor, esse mesmo poder ele não tem como exercer na imprensa, pois "a palavra dita e divulgada na mídia não teria jamais como ser reescrita

\footnotetext{
${ }^{13}$ Nosso debate teve como foco somente as correntes literárias Simbolista e Parnasianista de origem francesa e o Modernismo que se manifesta na Europa em 1890-1910, chegando ao Brasil somente na primeira metade do século XX.
} 
depois de publicada, ele mão teria o poder de recolher as edições [...] o que coloca o Vampiro em pé de igualdade com os mortais”. (ANDRIOLI, 2013, p.111).

Assim sendo as palavras contidas nos jornais trazem uma morte anunciada, e ele prefere manter sua imortalidade. Em contrapartida seu silêncio o imortaliza, o faz misterioso, e a imprensa vampiriza este comportamento, pois falar sobre quem não fala, requer novas técnicas jornalísticas, como fazer ficção, utilizando recursos que não são habituais, e a quietude de Dalton Trevisan nunca impediu que deixasse de ser assunto nos jornais.

Para Andrioli (2013, p.119 apud TREVISAN, Dalton 1991) outro aspecto a ser salientado é o eterno dilema da "repetição" e previsibilidade gerada por ela que recai sobre Dalton Trevisan:

Há anos que escreve ele o mesmo conto? Com pequenas variações, sempre o único João, a mesma bendita Maria. Perú bêbado que, no círculo de giz repete sem arte nem graça os passinhos iguais. Falta-lhe imaginação até para mudar o nome dos personagens.

Como pudemos observar, a imprensa faz de Dalton Trevisan um personagem, e as próprias críticas com relação à "repetição", com o passar do tempo se tornam elogios. Os críticos procuram reescrever-se, mas Dalton Trevisan não lhes deixa outra opção que repetir a mesma crítica sobre a repetição. Assim, exaurindo-se as argumentações jornalísticas, passam ao meio acadêmico e estudam a repetição a fim de transformá-la em algo de positivo, e a mesma passará a denominar-se estilo, virtude, estratégia, intencionalidade.

\section{REFERÊNCIAS}

- Alberto, J. O Vampiro de Curitiba - Dalton Trevisan, resumo biográfico. Disponível em http://www.procampus.com.br/vestibular/resumos/uespi2009/o\%20vampiro\%20de\%20curitiba.pdf. Texto de 2013. Acessado em 25/05/2016.

- ANDRIOLI, L. O Silêncio do Vampiro: o discurso jornalístico sobre Dalton Trevisan. Curitiba: Editora Kafka, 2013.

- BEGA, M.T.S. Letras e Política no Paraná - Simbolistas e Anticlericais na República Velha, ed. UFPR, Curitiba, 2013.

- FABRINO, A.M.J. História da literatura universal. Curitiba Editora Intersaberes, Curitiba, 2014. 
- MONTEIRO, S.D.J. O Vampiro não lê jornal... Ah é? A crítica de jornal e o dilema da repetição na obra de Dalton Trevisan. Curitiba: Instituto Memória, 2013.

MELlO, S.G.B. Esses moços do Paraná: livre circulação da palavra nos albores da República. Florianópolis: Tese de Doutorado História/UFSC, 2008.

- NUNES FILHO, Milton. Dalton Jérson Trevisan. http://www.recantodasletras.com.br/biografias/235493. Texto de 2006. Acessado em 26/05/2016.

- OLIVEIRA, Luiz Claudio Soares de. Joaquim contra o Parnasianismo. Curitiba: Mestrado em Estudos Literários, 2005.

- VANALI, Ana Crhistina. A erva-mate e a política paranaense. Curitiba: Instituto Memória, 2013.

- VIEIRA, C.E. Educação e Modernidade no projeto formativo de Erasmo Pilotto. Artigo: História e Historiografia da Educação, do Programa de Mestrado e Doutorado em Educação - Eixo Temático 6: Intelectuais, pensamento social e educação da Universidade Federal do Paraná,- 2006.

\section{REVISTAS CONSULTADAS}

-TREVISAN, Dalton. Emiliano, poeta medíocre. IN: Joaquim - revista mensal de arte. Curitiba, junho de 1946. N. ${ }^{\circ} 2: 16$.

-TREVISAN, Dalton. IN: Joaquim - revista mensal de arte. Curitiba, junho de $1946 . \mathrm{N}^{\circ} 2$.

-TREVISAN, Dalton. IN: Joaquim - revista mensal de arte. Curitiba, julho de 1946. N³

\section{ENTREVISTA REALIZADA}

- Ivan Justen Santana, professor doutor e tutor do curso de Letras do Centro Universitário Internacional - UNINTER, pesquisador da literatura paranaense em entrevista cedida no dia 23/05/2016.

\section{OUTROS}

-TREVISAN, Dalton. Quem tem medo do Vampiro? Panfleto sem título sem data. Curitiba, 1991, sem editora. 


\section{Talk about Joaquim is talking about Dalton!}

\section{ABSTRACT}

The article discusses the magazine's trajectory Joaquim was born to break with a dominant hegemony that is imposed on paranaense literature for over half a century, the Paranismo, which through a local elite created and sponsored the field of the state's arts. Therefore, so that you can understand the changes experienced in the field of curitibanas literary currents, and the impact of Joaquim in Paraná society the years 1930/50, we will make a historical overview of the cultural environment so that we can contextualize the magazine's birth and in what way it can, at any given time to gather literary youth willing to break the domination of the then representative Paranista movement, making room for another form of literary expression, the modernists.

Keywords: Paranismo, Dalton Trevisan, Joaquim Magazine, Modernism Paranaense Literature. 